\section{MICROBIAL REDUCTION OF SYNTHETIC BIOGENIC IRON OXIDES CONTAINING VARIOUS AMOUNTS OF ORGANIC CARBON AND SILICA.}

\author{
MRS. DANIELA QUINTERO MORALES, PHD AND \\ DANIELLE FORTIN
}

University of Ottawa

Presenting Author: dquin020@uottawa.ca

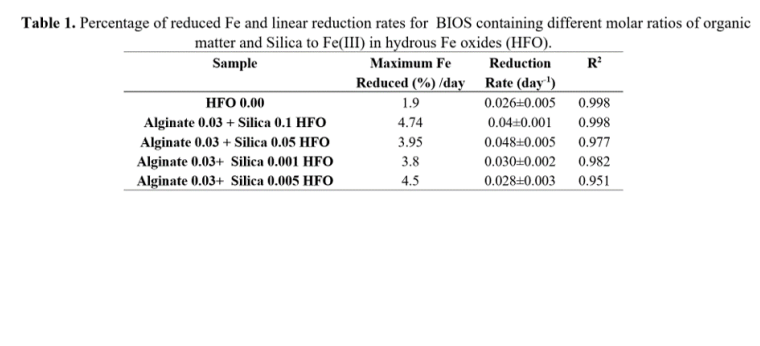

MICROBIAL REDUCTION OF SYNTHETIC
BIOGENIC IRON OXIDES CONTAINING VARIOUS
AMOUNTS OF ORGANIC CARBON AND SILICA.
QUINTERO D ${ }^{1}$, FORTIN D
1 University of Ottawa, Ottawa, Canada,
$\begin{aligned} & \text { dquin020@uottawa.ca } \\ & 2 \quad \text { University of Ottawa, Ottawa, Canada, }\end{aligned}$

danielle.fortin@uottawa.ca

Iron oxides formed in close association with bacteria are referred to as biogenic minerals (BIOS). Both the organic part of BIOS and the iron oxide particles affect the net surface charge of those iron-organic carbon aggregates and offer reactive sites that can immobilize many soluble contaminants ${ }^{[1]}$, making BIOS a contender in bioremediation technologies. However, before using BIOS in bioremediation, it is essential to understand the interactions between $\mathrm{Fe}$ and $\mathrm{C}$ and other minor components (including Silica) during BIOS formation and transformation through experimental approaches ${ }^{[2]}$. This project involves the synthesis of Biogenic Iron Oxides (BIOS) using various Silica contents and different soluble alginate concentrations (as an analogue for bacterial exopolysaccharides) close to natural environmental conditions. The mineralogical, chemical and physical composition of the synthesized samples was determined by X-Ray Diffraction (XRD) and scanning electron microscopy (SEM). The various samples (mainly ferrihydrite) were then reduced in the presence of Shewanella putrefaciens CN32, a well-known iron reducing bacteria. All microbial reduction experiments with different BIOS were performed under anoxic conditions in a chemically defined medium.

Preliminary results indicate that the ratio of organic matter and Silica to $\mathrm{Fe}$ (III) in BIOS affects the reduction rate. In some instances, samples in the presence of high concentration of Silica (i.e.,> 0.05) become more sensitive to microbial reduction than samples with the same concentration of alginate but with either lower (0.005 and 0.001) or higher (0.1) Silica contents. Additional work is underway in order to determine the exact role of Silica in BIOS reduction.

${ }^{[1]}$ Langley, et al. (2010). Environ. Sci. Technol. 43, 10081014.

${ }^{[2]}$ Dyer, et al. (2010). Science 348, 65- 70. 